\title{
Avaliação Geoecológica de Susceptibilidade à Ocorrência de Incêndios no Estado do Rio de Janeiro, Brasil
}

\author{
Manoel do Couto Fernandes ${ }^{1}$, Pedro Henrique Ferreira Coura ${ }^{1}$, \\ Gustavo Mota de Sousa ${ }^{2}$, André de Souza Avelar ${ }^{3}$
}

${ }^{1}$ Laboratório de Cartografia (GEOCART), Departamento de Geografia, Universidade Federal do Rio de Janeiro - UFRJ

${ }^{2}$ Departamento de Geociências, Instituto de Agronomia, Universidade Federal Rural do Rio de Janeiro - UFRRJ

${ }^{3}$ Laboratório de Geo-Hidroecologia (GEOHECO), Departamento de Geografia, Universidade Federal do Rio de Janeiro - UFRJ

\begin{abstract}
RESUMO
Os remanescentes florestais da Mata Atlântica têm sofrido pressões antrópicas frequentes. Essas pressões são relacionadas, principalmente, ao desmatamento e aos incêndios florestais. Por isso, o objetivo deste artigo é o desenvolvimento de um mapa geoecológico de susceptibilidade à ocorrência de incêndios no Estado do Rio de Janeiro, na escala de 1:100.000. Para esta proposta, mapas de elementos funcionais e de estrutura da paisagem (forma das encostas, radiação solar, uso da terra e balanço hídrico) foram construídos. O estudo foi conduzido utilizando o método analítico integrativo e diferentes técnicas de geoprocessamento, como Modelos Digitais de Elevação e Sistemas de Informações Geográficas. Os mapas representam três diferentes períodos: anual, seco e chuvoso. Ademais, estes mapas foram validados por meio dos dados do sensor MODIS. Os resultados proporcionaram diferentes arranjos espaciais para a susceptibilidade por meio das classes designadas como alta, média e baixa, que tiveram boa correlação com os dados de validação.
\end{abstract}

Palavras-chave: mapas geoecológicos, incêndios florestais, geoprocessamento.

\section{Geoecological Assessment of Wildfire Occurence Potentiality in the State of Rio de Janeiro}

\begin{abstract}
The remaining Atlantic Forest has frequently suffered anthropogenic pressures. These pressures are mainly related to deforestation and wildfires. The purpose of this paper was to develop a geo-ecological susceptibility map of fire occurrences in the State of Rio de Janeiro at 1:100,000 scale. To this end, maps of landscape functions and structures (landforms, solar radiation, land use and water balance) were constructed. The study was conducted using analytical integrative approach and different geo-processing techniques, such as digital elevation models and geographic information systems. These maps represent three different periods: annual, dry and rainy seasons. Moreover, they were validated through the analysis of MODIS sensor data. Results showed different spatial arrangements provided by the susceptibility of classes designated as high, medium and low sensitivity, which correlated well with the validation data.
\end{abstract}

Keywords: geo-ecological maps, wildfires, geo-processing. 


\section{INTRODUÇÃO}

As discussões acerca da temática de incêndios florestais vêm crescendo consideravelmente nas últimas décadas, como apresentam as discussões de Setzer (1999), Coura et al. (2009) e Sousa et al. (2010).

Autores como Bridgewater (1993), Coelho Netto et al. (2007) e Fernandes (2009) apresentam a utilização da geoecologia com suporte do geoprocessamento como alternativa metodológica para o desenvolvimento de estudos que buscam o entendimento da estrutura, da função e da dinâmica dos elementos da paisagem para definir a espacialização de fenômenos, como os incêndios. O geoprocessamento, como um conjunto de tecnologias, funciona como suporte nas soluções operacionais de análises geoecológicas. Nesse contexto, Menezes (2000) sugere que um dos produtos dessas análises são os mapas geoecológicos, que são instrumentos para a representação cartográfica de temas relacionados à análise de uma paisagem e configuram a cartografia geoecológica.

$\mathrm{Na}$ medida em que o mapeamento geoecológico combina diferentes temas de análises correspondentes ao entendimento de uma paisagem e considerando a susceptibilidade às características específicas da paisagem, independentemente da interação com elementos externos, procurou-se elaborar um instrumento que representasse a combinação dessas variáveis naturais.

Com essa perspectiva, o trabalho tem como objetivo construir cenários temporais de susceptibilidade à ocorrência de incêndios no Estado do Rio de Janeiro, a partir de uma abordagem geoecológica apoiada em diferentes geotecnologias de geoprocessamento, tendo a escala de 1:100.000 como escala cartográfica de análise.

\section{MATERIAIS E MÉTODOS}

De uma maneira geral, é possível caracterizar o trabalho por meio de uma estrutura metodológica que parte da elaboração e da utilização de mapeamentos de alguns elementos estruturais e funcionais (Uso e Cobertura do Solo 2007, Modelo Digital de Elevação, Combustibilidade, Radiação Solar, Forma das Encostas e Balanço Hídrico) que, por meio do método analítico-integrativo (Coelho Netto et al., 2007), deram origem aos mapas geoecológicos de susceptibilidade à ocorrência de incêndios nos períodos anual, seco e úmido.

Esquematicamente, a construção dos mapas geoecológicos de susceptibilidade à ocorrência de incêndios seguiu procedimentos que compõem três etapas distintas (Figura 1).

\begin{tabular}{|c|c|c|}
\hline Dados de entrada & $\begin{array}{c}\text { Mapas de elementos } \\
\text { estruturais e funcionais }\end{array}$ \\
\hline
\end{tabular}

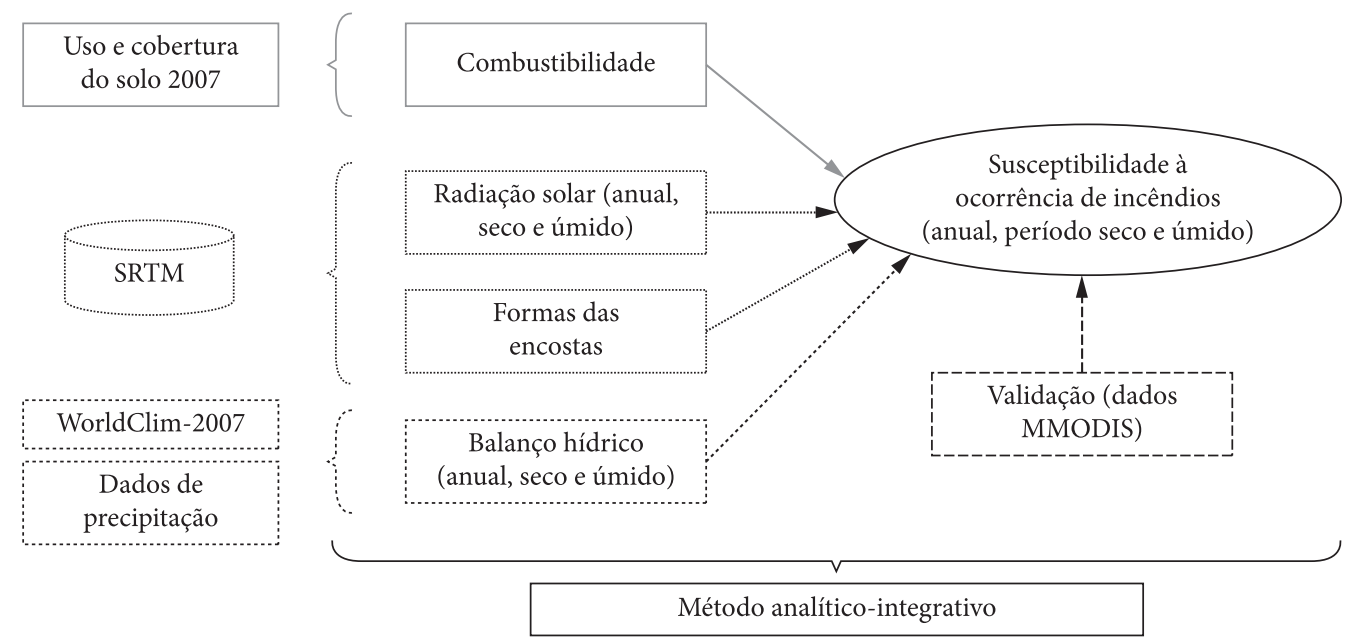

Figura 1. Esquema da geração do mapa de susceptibilidade à ocorrência de incêndios.

Figure 1. Schema to susceptibility wildfire occurrence map generation. 
A primeira etapa refere-se a aquisição e definição dos dados de entrada, ou seja, os dados utilizados para a confecção dos mapas de elementos estruturais e funcionais. Os elementos utilizados como dados de entrada foram: o mapa de uso e cobertura do solo (2007), o Modelo Digital de Elevação, obtido por interferometria, SRTM (Shuttle Radar Topographic Mission), dados de temperatura média mensal do WorldClim (2009) e dados pluviométricos do HidroWeb/ANA (Agência..., 2009).

$\mathrm{Na}$ segunda etapa, foram elaborados os mapas de elementos estruturais e funcionais. O mapa de combustibilidade foi definido a partir da aglutinação das classes do mapa de uso e cobertura do solo de 2007 (Figura 2), de acordo com a combustão da biomassa existente, como definido por Silva et al. (2009) e Sousa et al. (2010). Vale ressaltar que o mapa de Uso e Cobertura do Solo de 2007 (Figura 3) foi desenvolvido pelo Grupo de Sensoriamento Remoto (ESPAÇO) da Universidade Federal do Rio de Janeiro (Cruz et al., 2009), para atender a demanda do Zoneamento Ecológico-Econômico do Estado do Rio de Janeiro (Zoneamento..., 2009).

Uso e cobertura do solo (2007)

Reflorestamento

Pastagem em várzea

Pastagem

Agricultura (cana de açúcar)

Vegetação secundária em estágio inicial Restinga

Agricultura (café)

Manguezal

Floresta

Agricultura (cítricos - coco)

Agricultura (pequeno porte)

Áreas úmidas

Água

Solo exposto

Cordões arenosos

Afloramentos de rocha

Ocupação urbana de baixa densidade

Ocupação urbana de média densidade

Ocupação urbana de alta densidade

Figura 2. Classes de uso e cobertura do solo de acordo com sua combustibilidade.

Figure 2. Land cover and use category according to their combustibility.
O Modelo Digital de Elevação (SRTM) serviu como insumo para a extração dos mapas de morfologia das encostas e radiação solar. Este modelo foi adquirido diretamente da National Aeronautics and Space Administration (National..., 2009) e previamente pós-processado para a retirada de vãos e outros pontos espúrios, como valores extremamente altos (picos) ou extremamente baixos (vórtices). O mapa de forma das encostas tem como objetivo discriminar áreas com acúmulo e dispersão de fluxos, que são indicativos de áreas de maior e menor concentração de umidade. Essas áreas foram definidas, respectivamente, como côncavo e convexo.

A variável obtida pelo mapa de radiação solar é o total de radiação direta e difusa em watt hora por metro quadrado (Wh.m $\mathrm{m}^{-2}$ ). Esse mapa foi gerado por meio da extensão Spatial Analyst Tools do software ArcGis 9.3 (Environmental..., 2011). O ano base para este mapeamento foi 2007, referente aos períodos: anual, período seco (junho, julho e agosto) e período úmido (dezembro, janeiro e fevereiro). Essa variável é importante, pois aponta áreas com maior incidência de radiação, o que afeta diretamente o grau de umidade do sistema. Os valores de radiação foram classificados em alta, média e baixa radiação solar, de acordo com a quebra natural dos valores do histograma de frequência.

O mapa de Balanço Hídrico foi gerado a partir da diferença entre os dados de Precipitação Média (anual, período seco e úmido) e de Evapotranspiração Potencial (ETP) (anual, período seco e úmido) (Thornthwaite \& Mather, 1955). Os dados referentes à precipitação foram obtidos a partir da análise de 102 estações do sistema HidroWeb (Agência..., 2009), que dispunham de dados do período de 1977 a 2000. A partir destes, foi gerado um mapa de precipitação média para cada período de análise, por meio do método de krigagem e utilizando a resolução espacial de 30 arc-segundos $(\sim 1 \mathrm{~km})$. É importante ressaltar que os períodos da análise proposta (seco e úmido) foram delineados a partir da análise desses dados de precipitação.

A evapotranspiração potencial foi calculada pelo modelo de Thornthwaite (1948), utilizando os dados de temperatura média mensal do WorldClim com resolução espacial de 30 arc-segundos $(\sim 1 \mathrm{~km})$ (WorldClim, 2009). Esse método foi adotado, uma 


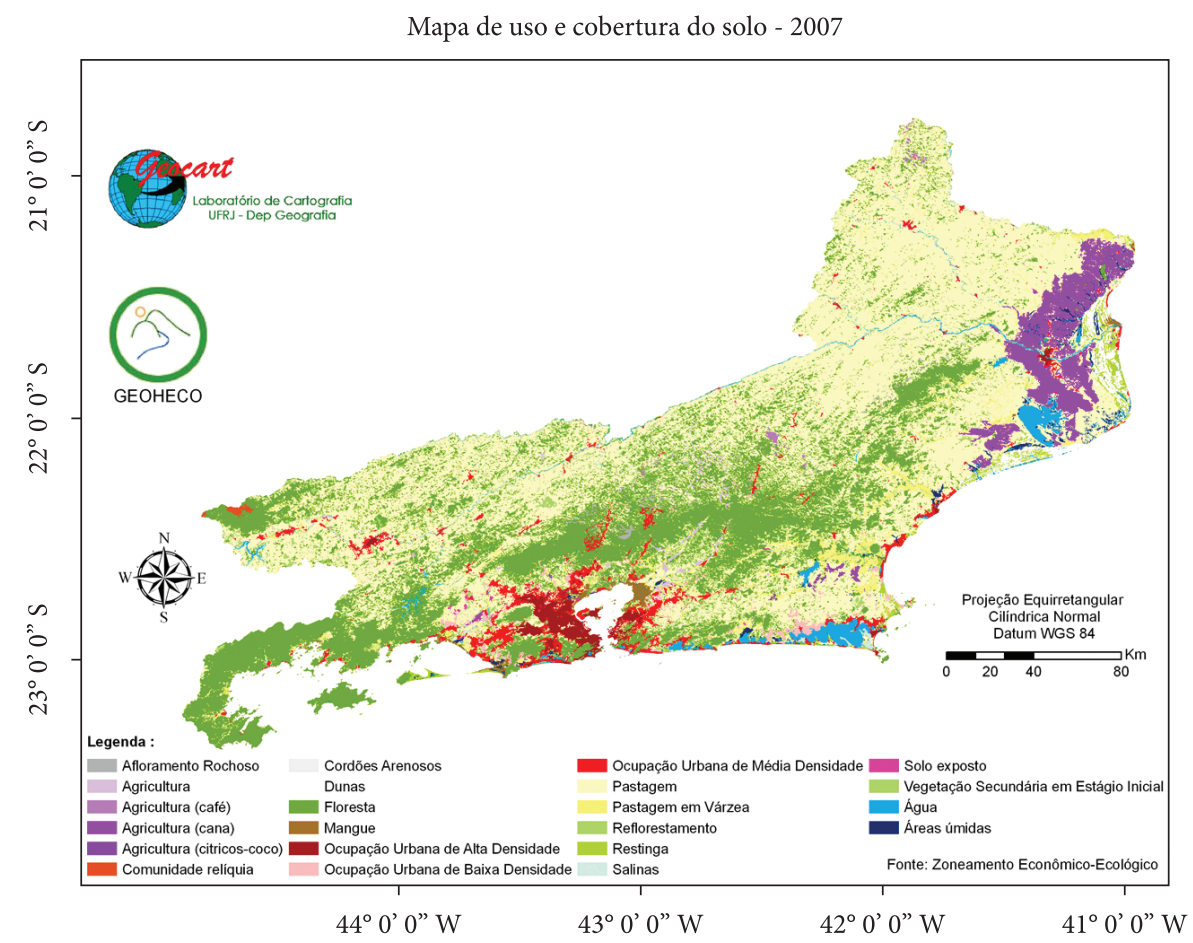

Figura 3. Mapa de uso e cobertura do solo 2007, Cruz et al. (2009).

Figure 3. Land cover and use map 2007, Cruz et al. (2009).

vez que utiliza como único parâmetro de entrada a temperatura média mensal, que foi o principal fator na escolha do método em virtude da escassa disponibilidade de dados, além de ser largamente utilizado em estudos de balanço hídrico. Vale ressaltar que esses dados de temperatura média mensal são médias históricas referentes ao período de 1950 a 2000.

O Balanço Hídrico é uma importante variável, pois aponta áreas com excesso, déficit hídrico e situações medianas, que afetam diretamente no grau de umidade do sistema. Possui a mesma periodicidade que o mapa de radiação e também foi classificado em três classes (alta, média e baixa) para os três períodos de análise. As classes de balanço hídrico anual são: baixa (2001,62-500 mm), média $(500--100 \mathrm{~mm})$ e alta $(-100--406,65 \mathrm{~mm})$. As classes em período seco foram: baixa (183,05-50 mm), média $(50--30 \mathrm{~mm})$ e alta $(-30--132,29 \mathrm{~mm})$. No período úmido, foram definidas as seguintes classes: baixa (838,37-300 mm), média (300-0 mm) e alta (0$-117,30 \mathrm{~mm})$.

A terceira e última etapa consiste na sobreposição dos mapas de Radiação Solar,
Morfologia das Encostas, Combustibilidade e Balanço Hídrico, utilizando técnicas de Sistema de Informações Geográficas e o método analíticointegrativo (Coelho Netto et al., 2007). Esse método se baseia no cruzamento de uma série de mapas básicos, cujas categorias são selecionadas segundo os conhecimentos das interações relevantes ao problema. Esses mapas podem ser simplificados por aglutinação de classes que possuam comportamento semelhante frente ao problema. Após a superposição por processos automáticos e utilizando esses conhecimentos básicos, o pesquisador pode interferir no traçado final das classes estabelecidas, corrigindo rumos e verificando a ocorrência dos resultados obtidos anteriormente. Dessa forma, foram gerados os três mapas geoecológicos de susceptibilidade à ocorrência de incêndios, na escala de 1:100.000, referentes aos períodos anual, seco e úmido.

As classes de susceptibilidade à ocorrência de incêndios foram definidas como alta, média e baixa susceptibilidade. É válido destacar a existência da classe de áreas não suscetíveis à ocorrência de incêndios (ANSOI). Esta classe foi criada em função da presença de áreas sem cobertura vegetal, definidas 
a partir do mapa de uso e cobertura do solo como áreas úmidas, urbanas, de água, de solo exposto, entre outras. Assim, como a proposta do trabalho se destina apenas a áreas com cobertura vegetal, as áreas sem cobertura foram retiradas da análise.

Ainda na terceira etapa, após a conclusão dos mapeamentos, estes foram validados a partir de dados diários de uma série de quatro anos (2004, 2005, 2006 e 2007) de focos de calor obtidos pelo sensor MODIS (Moderate Resolution Imaging Spectroradiometer). Os dados MMODIS utilizados no trabalho indicam as detecções de focos feitas pelo sistema da NASA e da Universidade de Maryland combinando todas as imagens do sensor MODIS das passagens diurnas dos satélites TERRA e AQUA e incluídas pelo Instituto Nacional Pesquisas Espaciais (INPE) no seu Banco de Dados de Queimadas (Instituto..., 2009).

Para realizar a validação, os dados MMODIS utilizados no trabalho foram separados de acordo com a periodicidade de cada realidade analisada, ou seja, os pontos foram separados em anuais (todos os pontos), período seco (pontos correspondentes aos meses de junho, julho e agosto) e período úmido (pontos correspondentes aos meses de dezembro, janeiro e fevereiro). Após esse refinamento, foi aplicado em todos esses pontos um buffer de $500 \mathrm{~m}$, contemplando assim uma área circular de $1 \mathrm{~km}$ de diâmetro, que foi denominada de áreas de buffer MMODIS. Utilizando esses dados em sobreposição com os mapas de susceptibilidade, pode-se observar o percentual de áreas em alta, média e baixa susceptibilidade.

Todos os procedimentos de tratamento e manuseio dos dados foram realizados no software ArcGis 9.3 da Environmental Systems Research Institute (2011) e possuem projeção Equirretangular Cilíndrica Normal, datum WGS84.

\section{RESULTADOS E DISCUSSÃO}

Inicialmente, buscou-se analisar a distribuição das classes de susceptibilidade (alta, média, baixa) nos diferentes períodos abordados anual (Figura 4), úmido (Figura 5) e seco (Figura 6).

$\mathrm{O}$ período anual apresenta a distribuição de classes mais homogênea em nível quantitativo. Tal fato ocorre porque a diferença de área

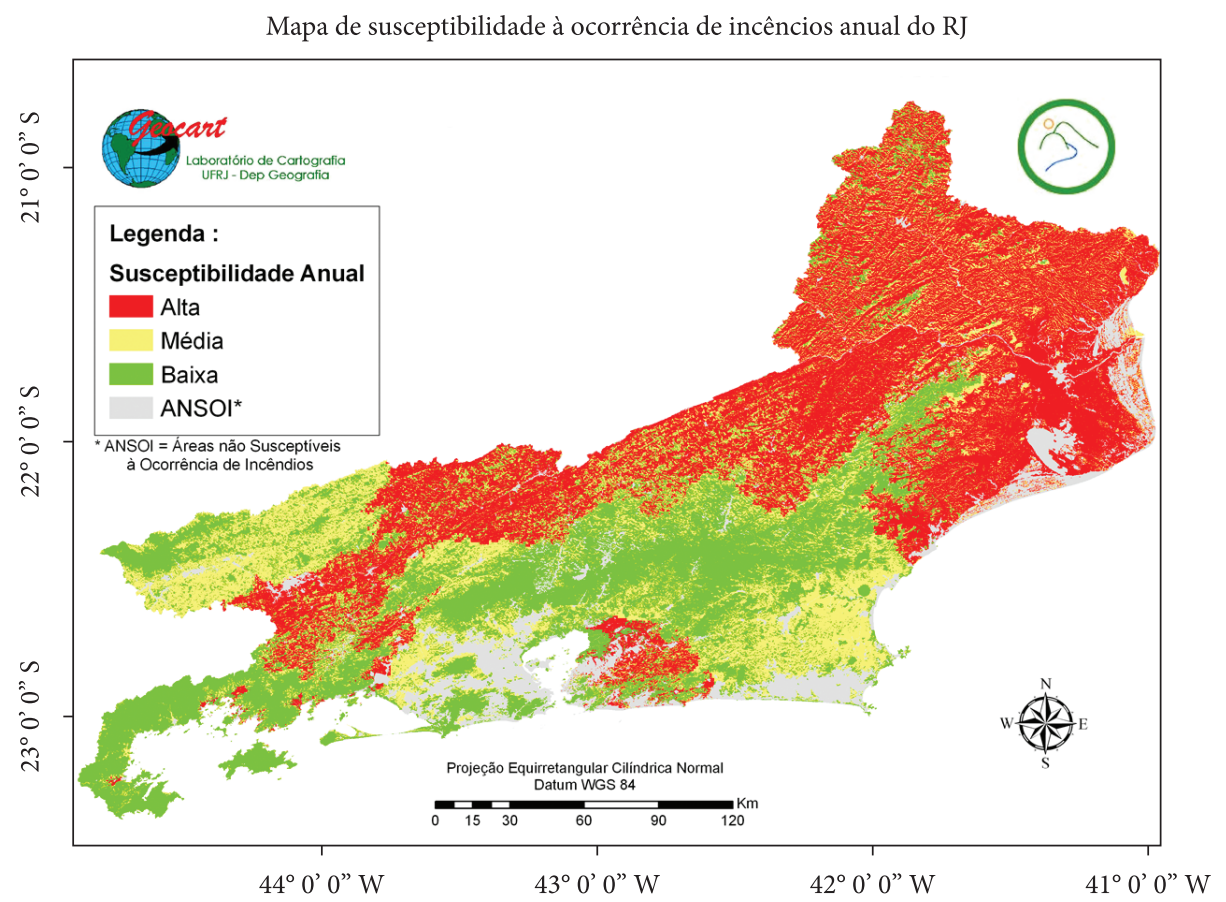

Figura 4. Mapa de susceptibilidade à ocorrência de incêndios anual.

Figure 4. Wildfire occurrence susceptibility map to year period. 


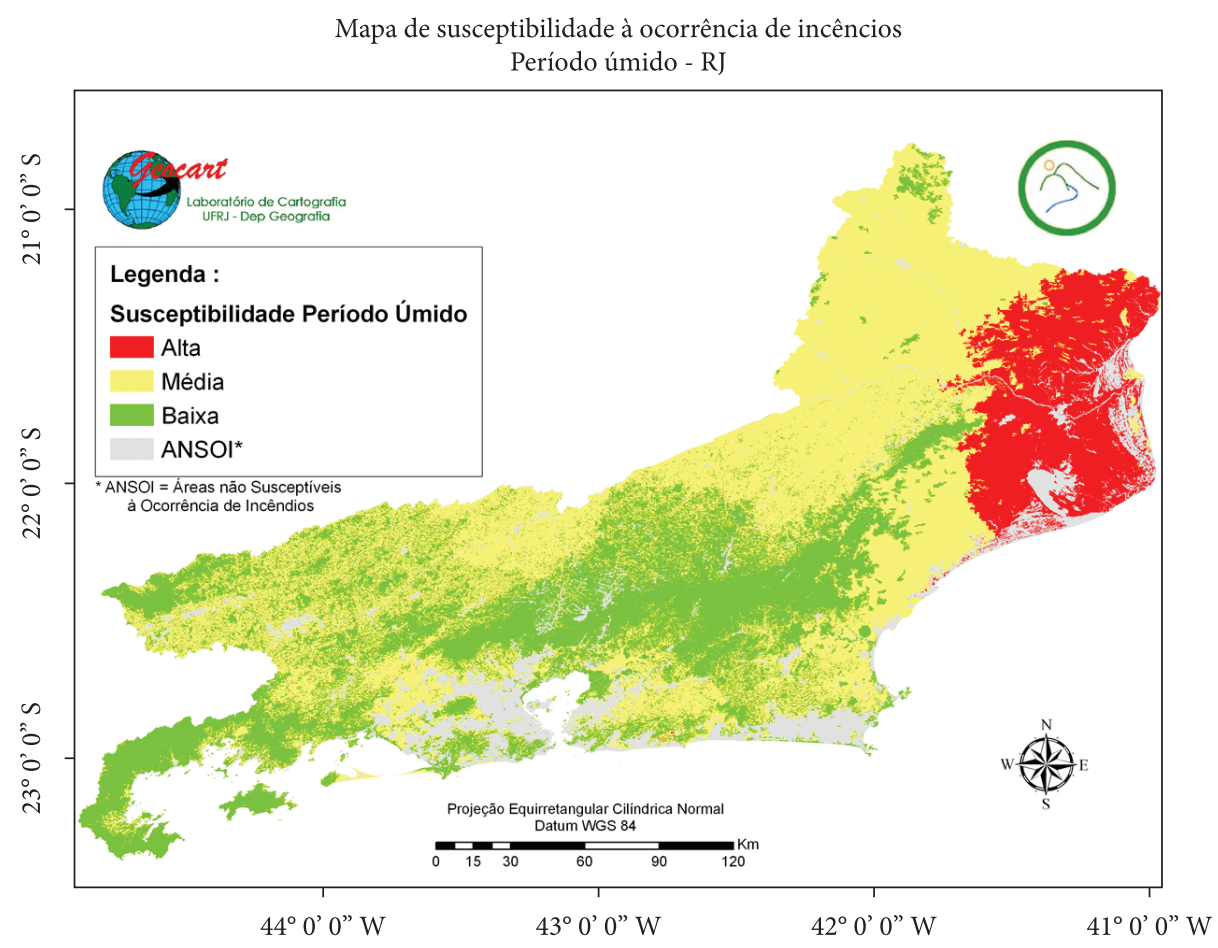

Figura 5. Mapa de susceptibilidade à ocorrência de incêndios - período úmido.

Figure 5. Wildfire occurrence susceptibility map - wet period.

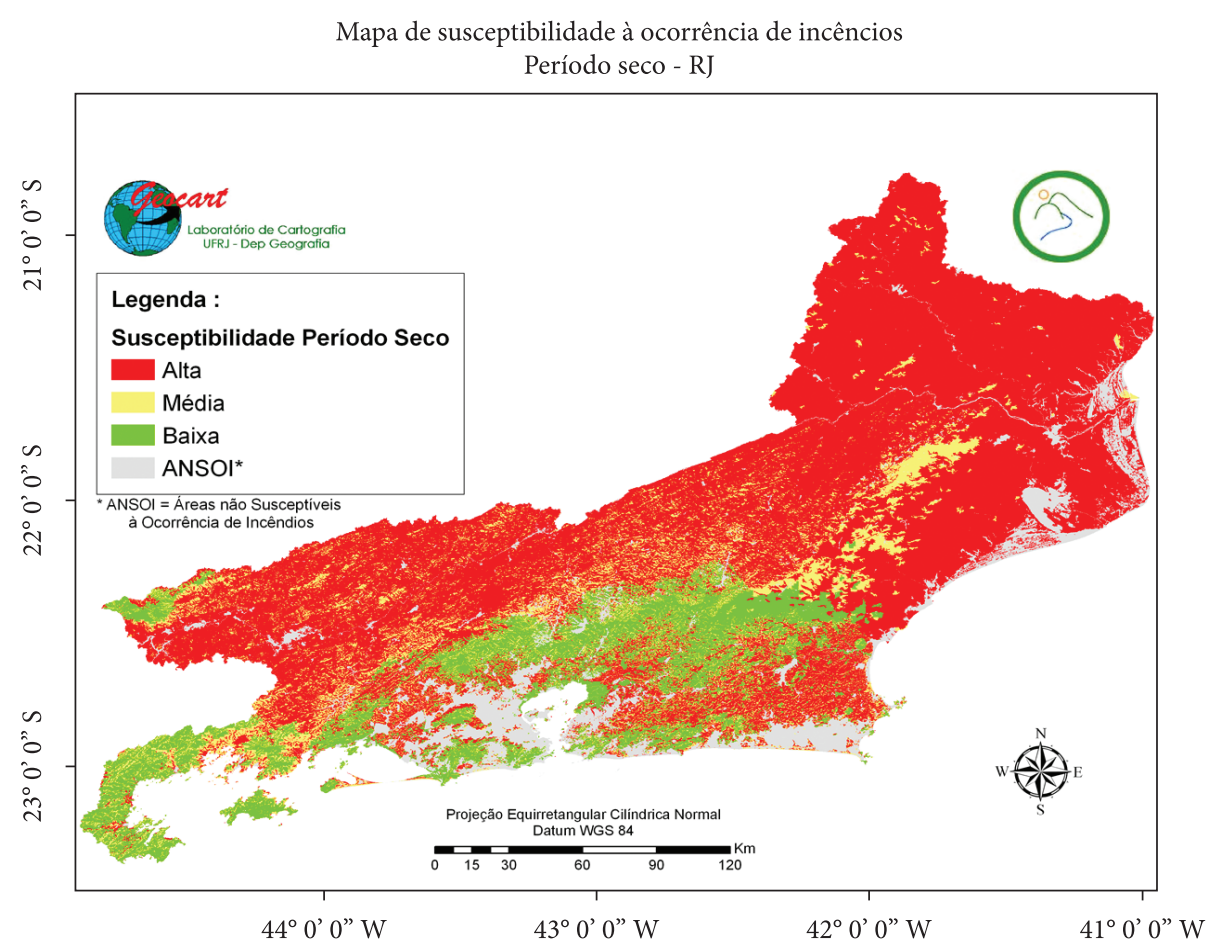

Figura 6. Mapa de susceptibilidade à ocorrência de incêndios - período seco.

Figure 6. Wildfire occurrence susceptibility map - dry period. 
ocupada entre as classes de alta, média e baixa susceptibilidade é menor que 10\% (Figura 7). Entretanto, em nível espacial, ocorre a concentração dessas classes em áreas mais específicas. A classe de alta susceptibilidade, que possui maior área de abrangência espacial, se concentra na região Norte Fluminense do Estado e em grande parte do vale do Rio Paraíba do Sul. Nestas, predominam as áreas de pastagem e encostas com alta incidência de radiação solar, além de ares com significativo déficit hídrico, que caracterizam as áreas de maior susceptibilidade à ocorrência de incêndios no Estado. Já a região Serrana e a região Sul Fluminense são as que possuem menor susceptibilidade, onde se sobressaem áreas florestadas e encostas com menor incidência de radiação solar.

O período úmido possui a média susceptibilidade como classe mais significativa, correspondendo a $50,6 \%$ do total. Outra característica desse período é a percentagem da baixa susceptibilidade que, se comparada aos outros dois períodos estudados, é a mais representativa $(28,9 \%)$ (Figura 8 ). As áreas de alta susceptibilidade nesse mapeamento ficam restritas à região Norte Fluminense, nos arredores do município de Campos dos Goytacazes. Por outro lado, o período seco mostra maior predominância da classe de alta susceptibilidade, sendo esta responsável por $63,9 \%$ de toda a área mapeada (Figura 9). Nesse mapeamento, as áreas de alta susceptibilidade se espraiam por todo o Estado e é, neste período, a concentração dos focos de calor levantada a partir do Banco de Dados de Queimadas (Instituto..., 2009).

Distribuição das classes da susceptibilidade anual

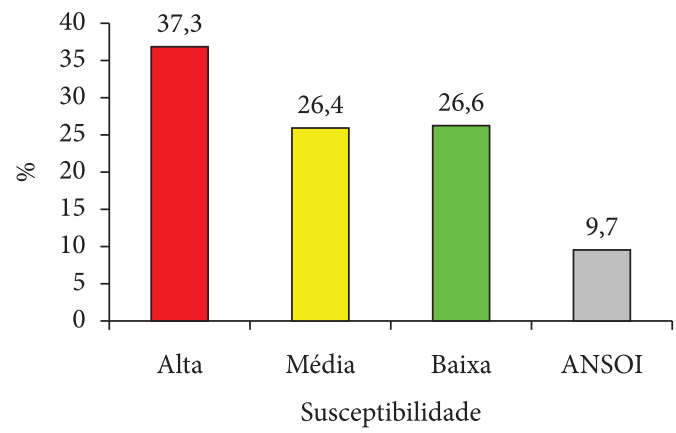

Figura 7. Gráfico de distribuição espacial de classes de susceptibilidade anual.

Figure 7. Graphic of susceptibility classes spatial distribution to year period.
Analisando-se a distribuição desses pontos de focos de calor (MMODIS), é possível perceber que seis municípios, dos 92 que compõem o Estado do Rio de Janeiro, concentram juntos $39,2 \%$ do total de 1.384 pontos de focos de calor do Estado. Esses municípios são: Campo dos Goytacazes (11,7\%); Volta Redonda (8,5\%); Petrópolis (5,6\%); Rio de Janeiro (5\%); Teresópolis (4,3\%), e Paraíba do Sul $(4,1 \%)$ (Figura 10). Essa concentração corrobora as interpretações feitas em relação aos mapeamentos de susceptibilidades apresentados.

A maior proporção de focos de calor no município de Campos dos Goytacazes, que apresenta boa parte de seu território nos três cenários em alta susceptibilidade, pode ser relacionada à ocorrência de grandes manchas de pastagem que ocorrem no município, conjugadas com áreas de alta

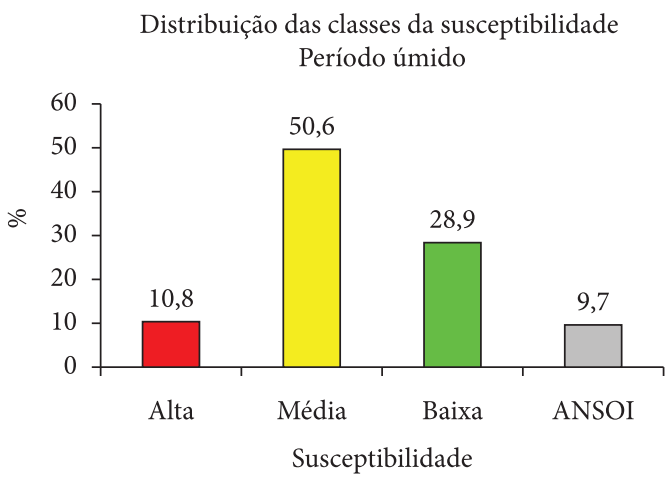

Figura 8. Gráfico de distribuição espacial de classes de susceptibilidade - período úmido.

Figure 8. Graphic of susceptibility classes spatial distribution - wet period.

Distribuição das classes da susceptibilidade Período seco

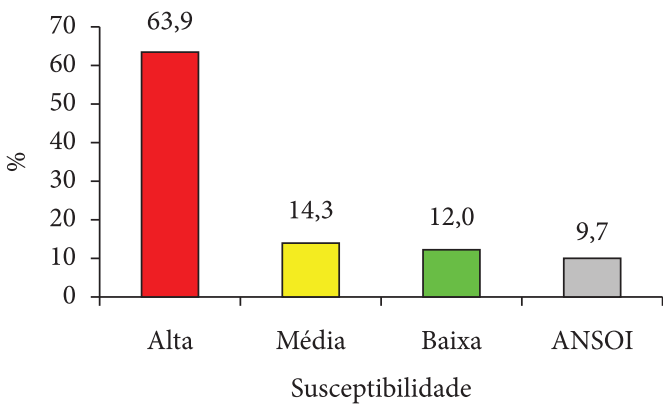

Figura 9. Gráfico de distribuição espacial de classes de susceptibilidade - período seco.

Figure 9. Graphic of susceptibility classes spatial distribution - dry period. 
concentração de radiação solar e índice bastante significativo de déficit hídrico. Soma-se a esse quadro o fato de esse município ser um grande produtor de cana-de-açúcar com manuseio baseado em queimadas.

Outra área de concentração é a bacia do Rio Paraíba do Sul, representada na Figura 11 pelos municípios de Volta Redonda, Paraíba do Sul e por parte dos municípios de Petrópolis e Teresópolis, que drenam para esta bacia. O município do Rio de Janeiro também ganha destaque nessa avaliação, com focos situados principalmente na zona oeste, onde se espraia a área agrícola do município.

Avaliando-se a interseção entre a distribuição espacial das áreas de buffer construídas a partir dos focos de calor (buffer MMODIS) e os mapeamentos de susceptibilidade construídos, foi possível verificar que, para o período anual, $46,7 \%$ se apresentaram na classe de alta susceptibilidade, $27,9 \%$ na média e apenas $17,9 \%$ na baixa (Figura 12). Por sua vez, o período úmido se destacou por apresentar um percentual maior de áreas de focos de calor

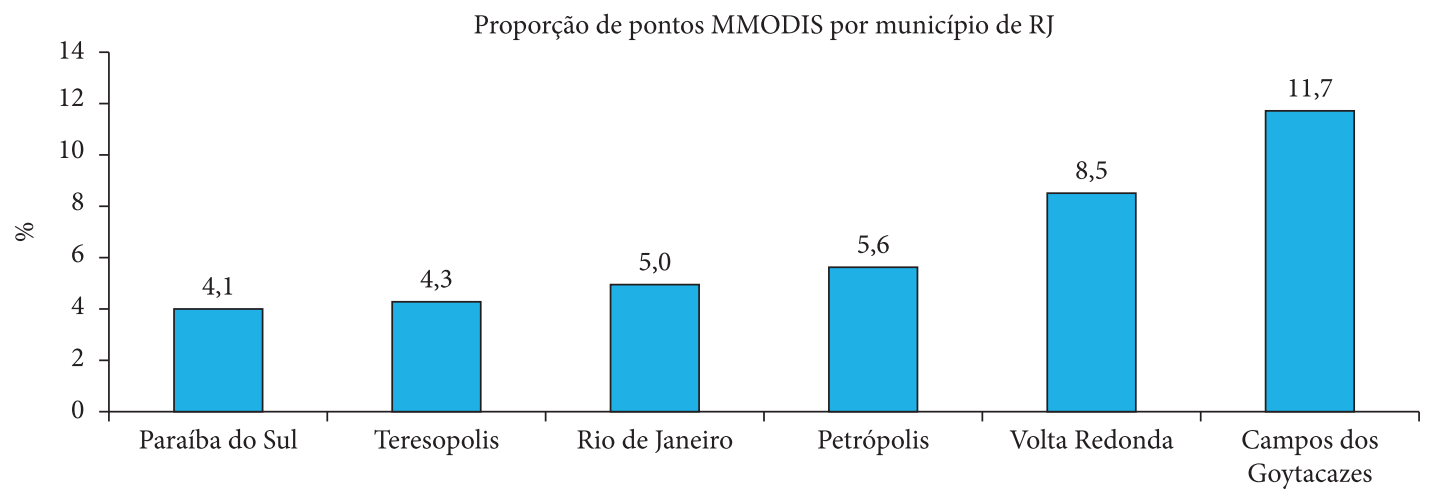

Figura 10. Gráfico da distribuição de pontos MMODIS nos municípios com maior concentração.

Figure 10. Graph of MMODID points distribution in the municipalities with higher concentration.

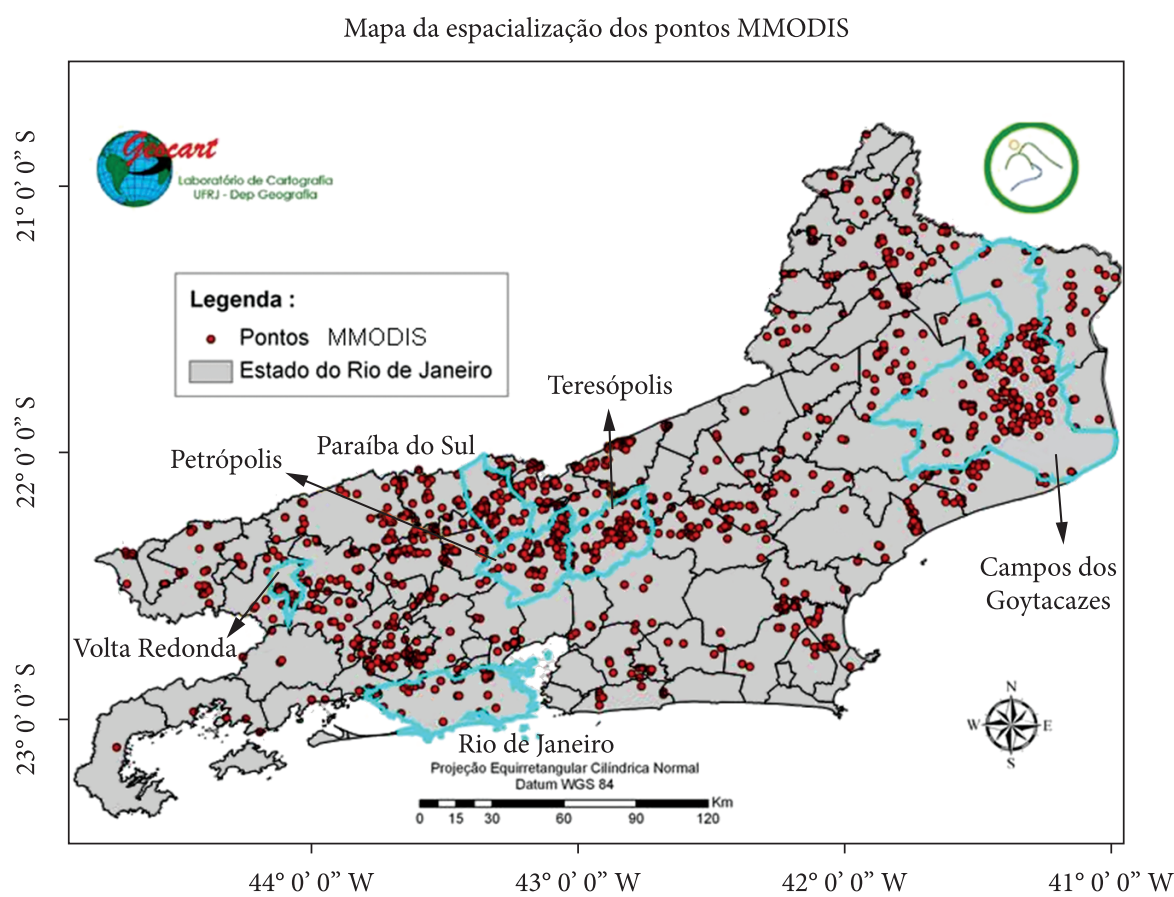

Figura 11. Mapa de distribuição de pontos MMODIS pelos municípios do Estado do Rio de Janeiro. Figure 11. MMODIS points distribution map by municipalities in the state of Rio de Janeiro. 
registrados nas classes de média susceptibilidade $(28,7 \%)$ e, além disso, percebe-se ainda que o percentual na alta susceptibilidade é o menor percentual, se comparado aos outros períodos analisados (Figura 13). Os resultados referentes ao período seco (Figura 14) apresentaram $72,7 \%$ das áreas na classe de alta susceptibilidade.

É válido ressaltar que, nos três períodos analisados, a classe de alta susceptibilidade apresentou correlação espacial de grande destaque em relação à ocorrência de focos de calor e a classe de baixa susceptibilidade sempre foi a de menor representatividade, excluindo as ANSOI.

Áreas de susceptibilidade anual validadas pelos dados MODIS

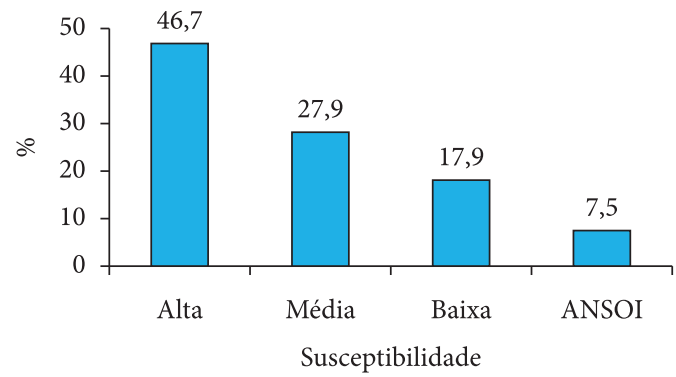

Figura 12. Gráfico da interseção entre a distribuição espacial das áreas de buffer MMODIS com o mapeamento de susceptibilidade anual.

Figure 12. Chart of the intersection between the spatial distributions of MMODIS buffer with the mapping of annual susceptibility.

Áreas de susceptibilidade do período úmido validadas pelos dados MODIS

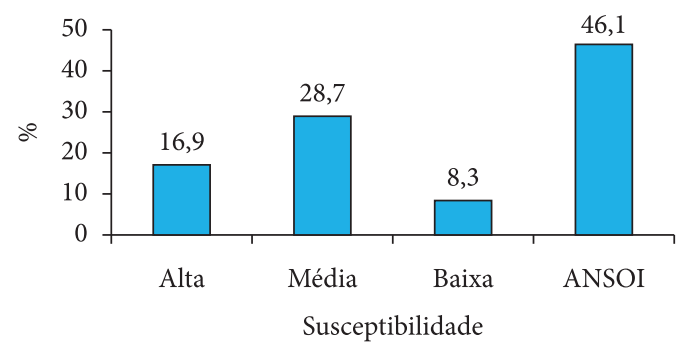

Figura 13. Gráfico da interseção entre a distribuição espacial das áreas de buffer MMODIS com o mapeamento de susceptibilidade - período úmido.

Figure 13. Chart of the intersection between the spatial distributions of MMODIS buffer with the mapping of susceptibility - wet period.
Esse quadro aponta a eficiência dos mapeamentos, principalmente se for caracterizado como áreas que mereçam atenção em relação à ocorrência de incêndios o agrupamento das áreas de média a alta susceptibilidade, como sugere Sousa et al. (2010). Entretanto, ajustes devem ser realizados para se buscar ajustar melhor os mapeamentos em face dos validadores. Ainda é importante ressaltar que os focos de calor apontam áreas com altas respostas em relação à detecção de calor que não necessariamente são áreas de incêndios. Essa é uma possível explicação da concentração de focos em áreas ANSOI.

\section{CONCLUSÕES}

Os mapeamentos de susceptibilidade à ocorrência de incêndios gerados se apresentam como um novo instrumento de auxílio no combate a um dos principais vetores de modificação da paisagem do Estado do Rio de Janeiro. Merece destaque o caráter diferencial da abordagem adotada, pois a grande maioria dos estudos conduzidos no território nacional atua na detecção do incêndio e não na construção de cenários que apontam áreas susceptíveis a ocorrência desse fenômeno. Assim, ressalta-se a importância do estudo em função da perspectiva prognóstica assumida.

É importante enfatizar que a metodologia de construção dos mapeamentos não é fechada e ainda necessita abordar outros fatores ambientais, como a ocorrência de ventos terrais, para tentar torná-la

Áreas de susceptibilidade do período seco validadas pelos dados MODIS

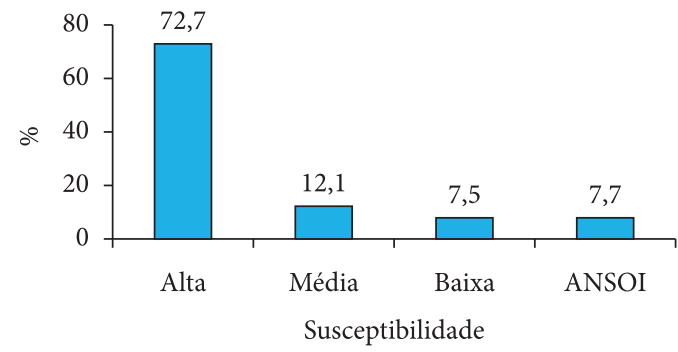

Figura 14. Gráfico da interseção entre a distribuição espacial das áreas de buffer MMODIS com o mapeamento de susceptibilidade - período seco.

Figure 14. Chart of the intersection between the spatial distributions of MMODIS buffer with the mapping of susceptibility - dry period. 
ainda mais eficiente na construção de modelos de representação de susceptibilidade à ocorrência de incêndios. Entretanto, os resultados se mostraram satisfatórios tanto em relação à representatividade dos mapeamentos em função da realidade de cada uma das situações analisadas e a espacialização alcançada quanto em face da validação realizada por meio dos dados do sensor MODIS. Porém, é importante salientar que esses dados utilizados na validação registram focos de calor e não focos de incêndio, ou seja, podem estar associados a qualquer outra superfície que emane calor. Além disso, esse foco de calor não necessariamente contempla toda a área de um quilômetro quadrado, como assumido no trabalho.

Todavia, os mapas elaborados podem servir como instrumento de auxílio à elaboração de estratégias de alerta e combate aos incêndios florestais no Estado do Rio de Janeiro. Além disso, a metodologia se mostra simples e passível de utilização em outras áreas com a mesma problemática.

\section{AGRADECIMENTOS}

Os autores deste artigo agradecem à FAPERJ e ao $\mathrm{CNPq}$ pelo financiamento da pesquisa.

\section{STATUS DA SUBMISSÃO}

Recebido: 29/07/2011

Aceito: 21/09/2011

Resumo publicado online: 27/09/2011

Artigo completo publicado: 30/09/2011

\section{AUTOR(ES) PARA CORRESPONDÊNCIA}

\section{Manoel do Couto Fernandes}

Laboratório de Cartografia, Departamento de Geografia, Centro de Ciências Matemáticas e da Natureza CCMN, Instituto de Geociencias - IGEO, Universidade Federal do Rio de Janeiro - UFRJ, Av. Athos da Silveira Ramos, 274, Bloco H1, Sala 017, Cidade Universitária, CEP 21949-900

Rio de Janeiro, RJ, Brasil e-mail: manoel.fernandes@ufrj.br

\section{Pedro Henrique Ferreira Coura}

Laboratório de Cartografia,

Departamento de Geografia,

Centro de Ciências Matemáticas e da Natureza -

CCMN, Instituto de Geociencias - IGEO,

Universidade Federal do Rio de Janeiro - UFRJ,

Av. Athos da Silveira Ramos, 274, Bloco H1,

Sala 017, Cidade Universitária, CEP 21949-900

Rio de Janeiro, RJ, Brasil

e-mail: ped.coura@gmail.com

\section{REFERÊNCIAS}

Agência Nacional de Águas - ANA (Brasil). HidroWeb - sistema de informações hidrológicas. [cited 2009 out. 20]. Available from: http://hidroweb.ana.gov.br/.

Bridgewater PB. Landscape ecology, geographic information systems and nature conservation. In: Haines-Young R, Green DR, Cousins SH, organizadores. Landscape Ecology and GIS. Taylor and Francis; 1993. cap. 3, p. 23-36.

Coelho Netto AL, Avelar AS, Fernandes MC, Lacerda, W.A. Landslide susceptibility in a mountainous geoecosystem, Tijuca Massif, Rio de Janeiro: The role of morphometric subdivision of the terrain. Geomorphology 2007; 87(3):120-131. http://dx.doi. org/10.1016/j.geomorph.2006.03.041

Coura PHF, Sousa GM, Fernandes MC. Mapeamento geoecológico da susceptibilidade à ocorrência de incêndios no maciço da Pedra Branca, município do Rio de Janeiro. Anuário do Instituto de Geociências 2009; 32 (2):14-25.

Cruz CBM, Rosário LS, Abreu MB, Almeida PMM, Vicens RS, Cronemberger FM. Classificação orientada a objetos na geração do mapa de uso e cobertura da terra do Estado do Rio de Janeiro In: Anais do XIV Simpósio Brasileiro de Sensoriamento Remoto SBSR; 2009; Natal. São José dos Campos: INPE; 2009. Artigos, p. 7789-7796. [cited 2010 dez. 7]. Available from: $\quad$ http://marte.dpi.inpe.br/col/dpi.inpe.br/ sbsr@80/2008/11.17.16.04.39/doc/7789-7796.pdf.

Environmental Systems Research Institute - ESRI. ArcGis Desktop 9.3 Help. [cited 2011 ago. 20]. Available from: http://webhelp.esri.com/arcgisdesktop/9.3/index. $\mathrm{cfm}$ ?topicname $=$ calculating\%20solar\%20radiation/.

Fernandes MC. Discussões conceituais e metodológicas do uso de geoprocessamento em análises geoecológicas In: Bicalho AMSM, Gomes PCC, organizadores. Questões metodológicas e novas temáticas na pesquisa geográfica. Rio de Janeiro: Publit; 2009. p. 280-299.

Instituto Nacional de Pesquisas Espaciais - INPE (Brasil). Banco de Dados de Queimadas: Monitoramento 
de Focos. [cited 2009 nov. 22]. Available from: http:// www.dpi.inpe.br/proarco/bdqueimadas/.

Menezes PML. A interface Cartografia-Geoecologia nos estudos diagnósticos e prognósticos da paisagem: um modelo de avaliação de procedimentos analíticointegrativos [tese]. Rio de Janeiro: Universidade Federal do Rio de Janeiro; 2000.

National Aeronautics and Space Administration NASA. Shuttle Radar Topography Mission Publication. [cited 2009 dez.10]. Available from: http://www2.jpl. nasa.gov/srtm/>.

Setzer A. Até onde vai a devastação da Amazônia. Ciência Hoje 1999; (152).

Silva LCV, Fernandes MC, Argento MSF. Mapa geoecológico de potencialidade à ocorrência de incêndios no Parque Nacional do Itatiaia/RJ. Revista Brasileira de Cartografia 2009; 61-3:285-292.
Sousa GM, Coura PHF, Fernandes MC. Cartografia geoecológica da potencialidade à ocorrência de incêndios: uma proposta metodológica. Revista Brasileira de Cartografia 2010; 62-1:277-289.

Thornthwaite CW. An approach toward a rational classification of climate. Geographical Review 1948; 38:55-94. http://dx.doi.org/10.2307/210739

Thornthwaite, C.W, Mather, JR. The water balance. Publications in Climatology. New Jersey: Drexel Institute of Technology; 1955. $104 \mathrm{p}$.

WorldClim. Global Climate Data. [cited 2009 nov. 22]. Available from: http://www.worldclim.org/.

Zoneamento Ecológico-Econômico do Rio de Janeiro - ZEE-RJ. Análise e qualificação sócio-ambiental do Estado do Rio de Janeiro (Escala 1:100.000) subsídios ao Zoneamento Ecológico-Econômico. 2009. [cited 2010 jan. 12]. Available from: http://www.semadur.rj.gov. br/pages/outros_projetos/outrosproj_pdbsepetiba_ zoneamneto.html. 